\title{
An empirical study to measure the relationship between management style and conflict management
}

\author{
Saeed Moghaddas Pour, Alireza Bakhshi Zadeh ${ }^{*}$ and Elham Barati
}

Department of Management and Economics,Tabriat Modarres University, Tehran, Iran

\begin{tabular}{|c|c|}
\hline A R T I C L E I N F O & AB S T RACT \\
\hline $\begin{array}{l}\text { Article history: } \\
\text { Received March 25, } 2012 \\
\text { Received in Revised form } \\
\text { May, 10, } 2012 \\
\text { Accepted } 12 \text { May } 2012 \\
\text { Available online } \\
\text { May } 172012 \\
\text { Keywords: } \\
\text { Leadership style } \\
\text { Conflict management } \\
\text { Task-oriented leadership } \\
\text { Relationship-oriented leadership }\end{array}$ & $\begin{array}{l}\text { Leadership plays an important role among five main components of management. These days, } \\
\text { many organizations try to resolve any existing conflicts through adapting an appropriate } \\
\text { leadership strategy. During the past few years, there are increasing interests in examining the } \\
\text { relationship between management style and conflict management. The proposed study of this } \\
\text { paper performs an empirical study to find the relationship between relationship-oriented } \\
\text { leadership style and solution-oriented strategy as well as between leadership style and conflict } \\
\text { management. The proposed study distributed a questionnaire among } 43 \text { managers who were in } \\
\text { different industries in west part of Iran. Most of the people who participated in our survey were } \\
\text { male and they were between } 25 \text { to } 30 \text { years old. The study considers relationship between } \\
\text { leadership style and conflict management, which includes the relationship between relationship- } \\
\text { oriented and task-oriented leaderships with avoiding conflict management strategy, solution and } \\
\text { control based conflict managements. The results confirmed that there is only a meaningful } \\
\text { relationship between relationship-oriented leadership with solution-based conflict management. } \\
\text { In other words, our survey indicates that when there is a conflict, management can handle the } \\
\text { problem using his/her relationship and find appropriate solution to resolve any possible conflict. }\end{array}$ \\
\hline
\end{tabular}

\section{Introduction}

Leadership style has been one of the most important issues among professional managers and any change in leadership style can significantly influence the success of business units. There are literally different ways to handle any existing conflict in organizations using various types of leadership style. Ayoko and Callan (2010) examined the influence of different leadership behaviors on outcomes in 97 teams. More specifically, they implemented the frameworks applied from investigations of transformational leadership and emotional leadership to study the influence of specific features of team leader style in assessing team performance, as well as impacting social outcomes for team members. 
According to their study, leader behaviors involved higher levels of emotional management were associated with improved levels of task performance. They also reported that higher levels of inspiration and communication of vision by leaders were directly influenced with lower levels of bullying by team members. Generally speaking, the relationship among task/relational conflict, transformational leadership, market orientation, and performance tends to be complicated. Menguc and Auh (2008) explained the relevance of nonlinear impacts in the context of how business units might improve their market orientation and performance. In fact, when it comes to manage different people from various nationalities, leadership style becomes very important.

Mäkilouko (2004) explained how to cope with multicultural projects in a case study of the leadership styles of Finnish projects management. Their study included various team members from FinnishChinese, Finnish-European, and Finnish-American cultural combinations. The Chinese team members were from Hong Kong with one team from Beijing, while three multicultural project leadership styles were detected where 40 out of 47 project leaders specified a solely task oriented leadership style. The same leaders also specified cultural blindness, parochialism, ethnocentrism, or in-group favoritism. The seven leaders who specified solely relationships' orientation, or both task and relationships' orientation, also specified cultural sympathy and three leadership strategies to maintain team cohesion and to prevent cross-cultural issues. It is more likely that they understood foreign cultures as a social phenomenon and could use that knowledge in leadership.

Nauman et al. (2010) investigated the relationship of empowerment, leadership style and customer service as a measure of efficient project management in projects. Their study investigated empowerment climate in less and more virtual projects. Moreover, the study examined moderating impacts of degree of vitality on the relationship between empowerment and leadership style. They used data collected from project management professionals working in five countries using linear regression and moderated regression analysis to analyze the proposed hypotheses. Their results explained that empowerment climate had substantial impacts on concern for task, concern for people and customer service and was higher in more virtual than less virtual projects.

Cummings et al. (2010) performed a systematic review on leadership styles and outcome patterns for nursing workforce and work environment. They performed a comprehensive study on 34,664 titles and abstracts and, using content analysis, they grouped 64 outcomes into five categories including staff satisfaction with work, role and pay, staff relationships with work, staff health and wellbeing, work environment factors, and productivity and effectiveness. Some of their results indicated that leadership styles focused on people and relationships were associated with higher nurse job satisfaction, whereas 10 studies were reported that leadership styles focused on tasks were associated with lower nurse job satisfaction. Klein et al. (2011) proposed that team leadership moderates the impacts of values diversity on team conflict. They reported significant, but opposite, moderating impacts of task-focused and person-focused leadership. They also reported task-focused leadership attenuated the diversity-conflict relationship, while person-focused leadership exacerbated the diversity-conflict relationship.

Hoozée and Bruggeman (2010) explained how collective worker participation and leadership style impact the emergence of operational improvements during the design process of a time-driven activity-based costing (ABC) accounting system in a case study setting. Their findings recommend that, for operational improvements to occure during the design process of ABC system, collective worker participation and appropriate leadership styles were indispensable.

Randeree and El Faramawy (2011) investigated Islamic perspectives on conflict management within project managed environments. They reported that existing research had not disclosed any study that investigated empirically the Islamic viewpoint on conflict management in contemporary organizational contexts but specified that conflict in Islam is inevitable and a part of human nature, 
and, if managed properly, can be positive and constructive. They tried to address this gap, by presenting an empirical study of Islamic models of conflict management and argued that the three Islamic models discussed, were partially and covertly in existence in environments not traditional to their own. They also found that there was a scope for investigating explicit applied aspects to these Islamic models.

One of important issues influencing leadership is the presence of different culture. Byrne and Bradley (2007) investigated how personal and national cultures affect leadership style. They explored the differences of the two components of cultures on effective leadership. When a conflict happens in a system, there are different methods for handling conflict in the system and depending leadership style.

\section{The proposed study}

The proposed study of this paper considers six hypotheses by investigating the relationship between leadership style and conflict management strategies. Table 1 shows details of our proposed study.

\section{Table 1}

The summary of different hypotheses

\begin{tabular}{lll}
\hline Leadership style & Relationship oriented & Task oriented \\
\hline \multirow{2}{*}{ Conflict management strategies } & H1:Avoidance & H4:Avoidance \\
& H2:Solution based & H5:Solution based \\
& H3:Control & H6:Control \\
\hline
\end{tabular}

As we can observe from the results of Table 1, the following six hypotheses are studied for the proposed study of this paper.

1. There is a meaningful relationship between relationship-oriented leadership with avoiding conflict management.

2. There is a meaning relationship between relationship-oriented leadership with solution-based conflict management.

3. There is a meaning relationship between relationship-oriented leadership with control-based conflict management.

4. There is a meaningful relationship between task-oriented leadership with avoiding conflict management.

5. There is a meaning relationship between task-oriented leadership with solution-based conflict management.

6. There is a meaning relationship between task-oriented leadership with control-based conflict management.

The proposed study of this paper uses Likert (Likert, 1932) based questionnaires to perform the survey. We use a sample size of 43 managers who work for different industries from various sectors including tile, food, cement, etc. In this study, there were 43 managers participated in our survey and 34 were male and 9 were female. In terms of their age, only one was younger than 25, 26 people were 25 to 35 years old, 13 were between 36 and 45 and 3 were older than 45 years old. The average age of the despondence was 25 to 30 years and the frequency was 60.5 percent. In terms of their job experiences, 9 managers had less than one year of job experience, 23 managers had between one to five years of job experience, 10 people had from 6 to 10 years of job experience and there was only one person with over 11 years of job experience. In summary, 53.5\% of the participants had from one to five years of job experience. In terms of educational background, 2 people could only finish high school, 14 people maintained a 2-year-college degree, 23 people had bachelor degree and 4 people 
had master degree. To validate the questionnaire we first distributed the questionnaire among 10 managers for one company and calculated Cronbach alpha (Cronbach, 1951) summarized in Table 2.

Table 2

Cronbach alpha

\begin{tabular}{lcc}
\hline & Number of questions & Cronbach alpha \\
\hline Relationship-oriented & 15 & 0.727 \\
Task-oriented & 20 & 0.878 \\
Leadership style & 35 & 0.890 \\
Conflict avoidance & 12 & 0.810 \\
Solution oriented & 11 & 0.791 \\
Control & 7 & 0.791 \\
Conflict management & 30 & 0.853 \\
\hline
\end{tabular}

As we can observe from the results of Table 2, all Cronbach alpha are well above the minimum acceptable level of 0.7 .

\subsection{Leadership style}

We have asked the participants on what kind of leadership they prefer to use and their feedbacks are summarized in Table 3 as follows,

Table 3

The frequency of preferred leadership style

\begin{tabular}{lccc}
\hline Leadership style & Frequency & Percentage & Accumulated \\
\hline Relationship oriented & 19 & 44.2 & 44.2 \\
Task oriented & 22 & 51.2 & 95.3 \\
Combined method & 2 & 4.7 & 100.0 \\
\hline Total & 43 & 100.0 & \\
\hline
\end{tabular}

As we can observe from the results of Table 3, while $51.2 \% \mathrm{f}$ of the participants preferred to use task oriented leadership style $44.2 \%$ of them prefer to use relationship oriented leadership style.

\subsection{Handling conflict}

Based on what we have explained, in the case of chaos, there are three strategies adapted to handle any possible conflict. Our participants mostly preferred solution oriented strategy to handle any possible conflict. Table 4 shows details of our survey in terms of their opinions on how to handle any conflict.

\section{Table 4}

The frequency of preferred methods for handling conflict

\begin{tabular}{lccc}
\hline Methods for handling conflict & Frequency & Percentage & Accumulated \\
\hline Avoidance & 2 & 4.7 & 4.7 \\
Solution strategy & 36 & 83.7 & 88.4 \\
Control & 5 & 11.6 & 100.0 \\
\hline Total & 43 & 100.0 & \\
\hline
\end{tabular}


Based on the results of Table 4, $83.7 \%$ of the participants preferred solution strategy, $4.7 \%$ chose avoidance and $11.6 \%$ attempted to control any conflict.

\section{The results}

In this section, we present details of our results for the implementation of Pearson correlation test for six hypotheses explained earlier. For all six hypotheses, null hypothesis represents that there was no difference between variables and the level of significance was five percent for all hypotheses.

Table 5

The results of testing various hypotheses

\begin{tabular}{rlccc}
\hline $\mathrm{H}$ & \multicolumn{1}{c}{ Null hypothesis } & Pearson test & Sig. value & Result \\
\hline 1 & $\begin{array}{l}\text { There is no meaningful relationship between leadership style } \\
\text { and conflict management }\end{array}$ & -0.042 & 0.791 & $\mathrm{H}_{0}$ accepted \\
2 & $\begin{array}{l}\text { There is no meaning relationship between relationship- } \\
\text { oriented leadership with avoiding conflict management. }\end{array}$ & -0.044 & 0.781 & $\mathrm{H}_{0}$ accepted \\
$3 \begin{array}{l}\text { There is no meaning relationship between relationship- } \\
\text { oriented leadership with solution-based conflict management. }\end{array}$ & 0.333 & 0.029 & $\mathrm{H}_{0}$ rejected \\
$4 \begin{array}{l}\text { There is no meaning relationship between relationship- } \\
\text { oriented leadership with control-based conflict management. }\end{array}$ & -0.138 & 0.376 & $\mathrm{H}_{0}$ accepted \\
\hline $\begin{array}{l}\text { There is no meaningful relationship between task-oriented } \\
\text { leadership with avoiding conflict management. }\end{array}$ & -0.057 & 0.716 & $\mathrm{H}_{0}$ accepted \\
$6 \begin{array}{l}\text { There is no meaning relationship between task-oriented } \\
\text { leadership with solution-based conflict management. } \\
\text { There is no meaning relationship between task-oriented }\end{array}$ & -0.093 & 0.554 & $\mathrm{H}_{0}$ accepted \\
$\quad$\begin{tabular}{l} 
leadership with control-based conflict management. \\
\hline
\end{tabular} & -0.023 & 0.883 & $\mathrm{H}_{0}$ accepted \\
\hline
\end{tabular}

As we can observe from the results of Table 5, expect one case, all other null hypotheses have been accepted and we can conclude that there is a meaningful relationship between relationship-oriented leadership with solution-based conflict management. In other words, our survey indicates that when there is a conflict, management can handle the problem using his/her relationship and find appropriate solution to resolve any possible conflict.

\section{Conclusion}

In this paper, we have presented an empirical study to find the relationship between relationshiporiented leadership style and solution-oriented strategy as well as between leadership style and conflict management. The proposed study distributed a questionnaire among 43 managers in Iran. Most of the people who participated in our survey were male and they were between 25 to 30 years old. The study considered relationship between leadership style and conflict management including the relationship between relationship-oriented and task-oriented leaderships with avoiding conflict management strategy, solution and control based conflict managements. The results confirmed that there was a meaningful relationship between relationship-oriented leadership with solution-based conflict management. In other words, our survey indicates that when there is a conflict, management can handle the problem using his/her relationship and find appropriate solution to resolve any possible conflict.

\section{Acknowledgment}

The authors would like to thank the people who participated in our survey and carefully helped us accomplish this survey. 


\section{References}

Ayoko, O.B., \& Callan, V.J. (2010). Teams' reactions to conflict and teams' task and social outcomes: The moderating role of transformational and emotional leadership. European Management Journal, 28(3), 220-235.

Byrne, G.J., \& Bradley, F. (2007). Culture's influence on leadership efficiency: How personal and national cultures affect leadership style. Journal of Business Research, 60(2), 168-175.

Cronbach, L. J. (1951). Coefficient alpha and the internal structure of tests. Psychometrika, 16(3), 297-334.

Cummings, G.G., MacGregor, T., Davey, M., Lee, H., Wong, C.A., Lo, E., Muise, M., \& Stafford, E. (2010). Leadership styles and outcome patterns for the nursing workforce and work environment: A systematic review article. International Journal of Nursing Studies, 47(3), 363-385.

Hoozée, S., \& Bruggeman, W. (2010). Identifying operational improvements during the design process of a time-driven ABC system: The role of collective worker participation and leadership style. Management Accounting Research, 21(3), 185-198.

Likert, R. (1932). A Technique for the Measurement of Attitudes. Archives of Psychology, 140, 1-55.

Klein, K.J., Knight, A.P., Ziegert, J.C., Lim, B.C., \& Saltz, J. L. (2011). When team members' values differ: The moderating role of team leadership. Organizational Behavior and Human Decision Processes, 114(1), 25-36

Menguc, B., \& Auh, S. (2008). Conflict, leadership, and market orientation. International Journal of Research in Marketing, 25(1), 34-45.

Mäkilouko, M. (2004). Coping with multicultural projects: the leadership styles of Finnish project managers. International Journal of Project Management, 22(5), 387-396.

Nauman, S., Khan, A.M., \& Ehsan, N. (2010). Patterns of empowerment and leadership style in project environment. International Journal of Project Management, 28(7), 638-649.

Randeree, K., \& El Faramawy, A.T. (2011). Islamic perspectives on conflict management within project managed environments. International Journal of Project Management, 29(1), 26-32. 